\title{
STUDI KUALITATIF ANALISIS IMPLEMENTASI STANDAR PELAYANAN ANTENATAL CARE 10 TERPADU PADA IBU HAMIL DI PUSKESMAS BUNGUS KOTA PADANG TAHUN 2019
}

\author{
Dessy Elvira ${ }^{1}$ Defrin ${ }^{2}$ Erwani $^{3}$ \\ ${ }^{1,2}$ Fakultas kedokteran Univrsitas Andalas Padang Jalan perintis Kemerdekaan Jati Baru Padang \\ Sumatera barat kode pos 25129 , \\ ${ }^{3}$ Prodi D III Kebidanan Poletekkes Kemenkes Padang Jl. Raya Siteba Surau Gadang Kecamatan \\ Nanggalo Padang Sumatera Barat Kode Pos 25146 \\ E-mail: dessyelvira0@gmail.com
}

\section{STUDI KUALITATIF ANALISIS IMPLEMENTASI STANDAR PELAYANAN ANTENATAL CARE 10 TERPADU PADA IBU HAMIL DI PUSKESMAS BUNGUS KOTA PADANG TAHUN 2019}

\begin{abstract}
According to the World Health Organization (WHO) Report of 2014. Maternal mortality (AKI) in the world is 289,000 inhabitants. An effort to decline AKI as a priority program in health development by using standard care at least 10 integrated. The purpose of this research is to analyse the implementation of the standard of service of antenatal care 10 integrated with the health quality of pregnant women in the workplace Puskesmas Bungus Padang City Year 2019. This method of study is qualitative descriptive. The informant consists of the head of health centers, KIA program holders, midwives Puskesmas and pregnant women. Input analysis results of the implementation of ANC 10 integrated to improve human resources midwives have been following the training of antenatal 10 integrated services, the facilities have been complete and functioning properly. The SOP of antenatal service has been adjusted to 10T service standards and has been renewed every 3 years. The planning of antenatal service 10 integrated through the workshop of mini-level Puskesmas and through intersectoral deliberations. Barriers to the implementation of service is less maximum service from midwives in Puskesmas because of excessive workload, the reach of home residents away from Puskesmas while the availability of time of visit and service is insufficient. It is recommended that training on integrated antenatal service 10 be conducted periodically and continuously so that all health midwives can participate in the training directly
\end{abstract}

Key word : Qualitatif study, ANC, 10 Standart

\begin{abstract}
Abstrak
Menurut laporan World Health Organization (WHO) tahun 2014. Angka Kematian Ibu (AKI) di dunia yaitu 289.000 jiwa. Upaya penurunan AKI sebagai program prioritas dalam pembangunan kesehatan dengan menggunakan asuhan standar minimal 10 Terpadu. Tujuan penelitian ini adalah untuk menganalisis implementasi standar pelayanan antenatal care 10 Terpadu dengan kualitas kesehatan ibu hamil di wilayah
\end{abstract}


kerja Puskesmas Bungus Kota Padang tahun 2019.Metode penelitian ini yaitu deskriptif kualitatif. Informan terdiri dari kepala Puskesmas, pemegang program KIA, Bidan Puskesmas dan ibu hamil.Hasil analisis input pelaksanaan ANC 10 terpadu menunjukkan untuk meningkatkan sumber daya manusia bidan sudah mengikuti pelatihan pelayanan antenatal 10 Terpadu, sarana yang dimiliki sudah lengkap dan berfungsi dengan baik. SOP pelayanan antenatal sudah disesuaikan dengan standar pelayanan $10 T$ dan mengalami pembaharuan setiap 3 tahun sekali. Perencanaan pelayanan antenatal 10 Terpadu dilakukan melalui loka karya mini tingkat Puskesmas dan melalui musyawarah dengan lintas sektoral. Hambatan implementasi pelayanan yaitu kurang maksimalnya pelayanan dari Bidan di Puskesmas karena beban kerja yab berlebih, jangkauan rumah penduduk yang jauh dari Puskesmas sementara ketersediaan waktu kunjungan dan pelayanan tidak mencukupi. Disarankan agar pelatihan tentang pelayanan antenatal 10 Terpadu dilakukan secara berkala dan berkesinambungan sehingga semua Bidan Puskesmas dapat mengikuti pelatihan tersebut secara langsung.

Kata kunci: Studi kualitatif, ANC, 10 Standar

\section{PENDAHULUAN}

Upaya memperbaiki kesehatan ibu, bayi baru lahir dan anak telah menjadi prioritas utama dari pemerintah. Salah satu bentuk kebijakan program upaya penurunan AKI adalah dengan kebijakan pelayanan antenatal Kunjungan 1 (K1) dan Kunjungan 4 (K4). Pelayanan antenatal (antenatal carel ANC) penting untuk memastikan kesehatan ibu selama kehamilan dan menjamin ibu untuk melakukan persalinan di fasilitas kesehatan. Pelayanan antenatal diberikan oleh petugas kesehatan baik yang bekerja di instansi pemerintah maupun swasta. Pelayanan antenatalpun diberikan di Puskesmas-Puskesmas yang tersebar di Indonesia (Kemenkes RI, 2017).

Berdasarkan laporan dari Dinas Kesehatan Propinsi Sumatera Barat untuk target pencapaian program untuk K1 $=91 \%$ dan $\mathrm{K} 4=80 \%$. Tahun $2017 \mathrm{ibu}$ hamil yang ada di Provinsi Sumatera Barat sebanyak 120.868 orang dengan capaian K1 sebanyak 109.670 orang $(90.7 \%)$ dan K4 sebanyak 96.592 orang (79.9\%). Jika dibanding tahun 2015 capaian ini lebih kecil, yakni K1 = 99 $\%$ dan K4 = $89 \%$ (Dinkes Sumbar, 2017). Dinas Kesehatan Kota Padang menyatakan pada tahun 2017 kunjungan K1 mencapai 98\%, kunjungan K4 mencapai 96\%. Kematian ibu hamil dan bersalin ditemukan sebanyak 16 kasus, jumlah ini mengalami penurunan jika dibanding tahun 2016 (20 orang) (Dinkes Kota Padang, 2017).

Kendala yang dihadapi dalam pelaksanaan pelayanan kesehatan ibu hamil tidak hanya dari sisi akses. Kualitas pelayanan yang diberikan juga harus ditingkatkan, di antaranya pemenuhan semua komponen pelayanan kesehatan ibu hamil harus diberikan saat kunjungan. Dalam hal 
ketersediaan sarana kesehatan, hingga tahun 2017, terdapat 9.825 Puskesmas di Indonesia. Keberadaan puskesmas secara ideal harus didukung dengan aksesibilitas yang baik. Hal ini tentu saja sangat berkaitan dengan aspek geografis dan kemudahan sarana dan prasarana transportasi (Kemenkes RI, 2017).

Kunjungan antenatal untuk pemantauan dan pengawasan kesejahteraan ibu dan anak minimal empat kali selama kehamilan dalam waktu, yaitu sampai dengan kehamilan trimester I ( $<14$ minggu) satu kali kunjungan, dan kehamilan trimester II (14-28 minggu) satu kali kunjungan, dan kehamilan trimester III (28-36 minggu dan sesudah minggu ke-36) dua kali kunjungan. Secara nasional target kunjungan antenatal care adalah 90\%. Penilaian terhadap pelaksanaan pelayanan kesehatan ibu hamil dapat dilakukan dengan melihat cakupan K1 dan K4. (Kemenkes RI, 2017).

Upaya percepatan penurunan AKI telah dilakukan pemerintah Kota Padang dengan menjamin agar setiap ibu mampu mengakses pelayanan kesehatan ibu yang berkualitas dan mendapatkan standar pelayanan 10 Terpadu di setiap puskesmas. Sementara berdasarkan laporan terbaru dari Dinas Kesehatan Kota Padang tahun 2018, jumlah kematian ibu hamil dan nifas jauh mengalami penurunan, yakni sebanyak 5 orang, dengan rincian 1 orang di wilayah kerja Puskesmas Air Dingin, 1 orang di wilayah kerja Puskesmas Ikur Koto dan 3 orang di wilayah kerja Puskesmas Bungus. Dari data ini diketahui bahwa wilayah kerja Puskesmas Bungus masih memiliki permasalahan dalam usaha peningkatan derajat kesehatan pada ibu hamil dan nifas (Dinkes Kota Padang, 2017).

Puskesmas dalam memberikan pelayanan antenatal hendaknya menggunakan asuhan standar minimal 10 Terpadu yang telah ditetapkan yang dahulunya hanya 5 Terpadu, lalu berkembang menjadi 7 Terpadu.

Berdasarkan penelitian yang dilakukan oleh Mieke (2013) ditemukan hasil bahwa pelayanan antenatal terpadu malaria pada ibu hamil belum dilaksanakan oleh Bidan sesuai dengan pedoman penanganan dan pencegahan malaria pada ibu hamil. Hal ini dipengaruhi kurangnya tenaga bidan dan belum adanya SOP yang jelas dan banyak bidan yang belum mengikuti pelatihan tentang pencegahan dan penanganan malaria pada ibu hamil. Anastasia (2017) juga memaparkan hasil penelitian tentang ANC terpadu, dimana cakupan pelayanan antenatal di Kabupaten Jember masih rendah karena beberapa faktor 
yang berkaitan yaitu, Jumlah SDM yang masih kurang serta dana yang tersedia belum mencakup kebutuhan yang ada.

Berdasarkan uraian di atas, maka penulis ingin melakukan penelitian yang berjudul "Studi Kualitatif Analisis Implementasi Standar Pelayanan Antenatal Care 10 Terpadu dengan kualitas kesehatan ibu hamil di Puskesmas Bungus Kota Padang tahun 2019

\section{BAHAN DAN METODE PENELITIAN}

Metode penelitian yang digunakan adalah studi kualitatif Penelitian kualitatif Penelitian ini dilaksanakan di Puskesmas Bungus kota Padang.

Teknik pengambilan sampel yaitu purposive sampling sebanyak 19 orang.Instrumen penelitian yang digunakan dalam penelitian ini wawancara semi terstruktur dan FGD.Uji keabsahan data (triangulasi data ) meliputi uji, credibility, transferability, dependability, dan confirmability (Sugiyono, 2014).

Dalam penelitian kualitatif dikenal ada dua strategi analisis data yang sering digunakan bersama-sama atau secara terpisah yaitu model strategi analisis deskriptif kualitatif dan atau model strategi analisis verifikatif kualitatif. Analisis data kualitatif adalah upaya yang dilakukan dengan jalan bekerja dengan data, mengorganisasi data, memilah-milahnya menjadi satuan-satuan yang dapat dikelola. Proses analisis data meliputi pengumpulan data, menelaah data, reduksi data, penyajian data, dan pengambilan kesimpulan.

\section{HASIL DAN PEMBAHASAN}

\section{A. Komponen Input}

1. Tenaga Bidan

Menurut Permenkes RI No 1464 tahun 2010 tentang izin dan penyelenggaraan praktik bidan pasal 1 ayat 1 menyatakan bahwa bidan adalah seorang perempuan yang lulus dari pendidikan bidan yang telah teregistrasi sesuai ketentuan peraturan perundang-undangan. Berdasarkan hasil penelitian, diketahui bahwa jumlah tenaga bidan di Puskesmas Bungus sudah mencukupi yakni terdapat 20 orang bidan. Hal ini sejalan dengan standar ketenagaan Puskesmas dalam Lampiran Permenkes RI No 75 tahun 2014 yang menyatakan bahwa dalam Puskesmas rawat inap minimal terdapat 7 orang bidan Puskesmas.

Jadi dalam hal ini ketersediaan tenaga bidan sebagai pelayan kesehatan ibuibu hamil di Puskesmas Bungus sudah lebih dari cukup. Masing-masing bidan sudah diberi tugas dan tanggung jawab sesuai dengan pembagian kinerja yang disusun oleh 
petugas pemegang program kesehatan ibu dan anak. Sudah mencukupinya tenaga bidan juga berdampak pada sudah berjalannya setiap program pelayanan dengan baik dan memanfaatkan semua ketersediaan sarana dan prasarana pelayanan ANC 10 terpadu.

\section{Pengetahuan}

a. Pengetahuan bidan

Berdasarkan hasil penelitian diketahui bahwa informan utama mengetahui tentang definisi pelayanan antenatal 10 Terpadu, manfaat pelayanan antenatal 10 Terpadu, standar pelayanan antenatal 10 Terpadu di Puskesmas Bungus. Hasil penelitian Yuniasih (2011) menyatakan bahwa sumber daya manusia (SDM) adalah kecukupan baik kualitas maupun kuantitas implementor yang dapat melingkupi seluruh kelompok sasaran. Kualitas SDM dapat dilihat dari pengetahuan yang dimiliki oleh SDM tersebut. Berdasarkan hasil penelitian, informan utama memiliki pengetahuan yang baik dan hanya 1 memiliki pengetahuan yang cukup tentang pelayanan antenatal 10 Terpadu yang sesuai dengan standar yang ditetapkan oleh Dinkes Kota.

Hasil penelitian ini juga sesuai dengan hasil penelitian Dhiah (2010) yang menyatakan bahwa bidan yang memiliki pengetahuan yang cukup akan mampu melaksanakan pekerjaan sesuai standar meskipun latar belakang pendidikan adalah minimal D3 kebidanan.

Hal ini sesuai dengan teori perilaku Notoatmodjo (2007) yang menyebutkan bahwa pengetahuan atau kognitif merupakan domain yang sangat penting untuk terbentuknya tindakan seseorang (overt behaviour). Pengetahuan adalah hasil tahu dan ini terjadi setelah orang melakukan pengindraan terhadap suatu objek tertentu.

Berdasarkan analisa dari penelitian diketahui bahwa tingkat pendidikan yang dimiliki oleh bidan ternyata turut mempengaruhi tingkat pengetahuan mereka. Selain itu pengetahuan bidan tentang pelayanan antenatal care 10 terpadu juga ditunjang dengan pendidikan khusus melalui pelatihan-pelatihan dan seminar-seminar yang memang sering diadakan. Adanya berbagai pelatihan dan ditunjang dengan tingkat pendidikan yang tinggi tentu akan membawa dampak yang sangat baik terhadap peningkatan sumber informasi yang dimiliki oleh bidan dan pada akhirnya mampu menambah wawasan dan pemahaman mereka tentang pelayanan antenatal care 10 terpadu.

Sebagai upaya penunjang kualitas pelayanan pada ibu hamil, tentu tidak 
hanya terfokus pada pelaksanaan implementasi ANC 10 terpadu saja, faktor penunjang lain juga harus diperhatikan, salah satunya adalah kemampuan bidan dalam memahami psikologi pada ibu hamil yang datang berkunjung. Bidan berperan memberikan support dan dukungan moral bagi klien dalam menghadapi perubahan fisik dan adaptasi psikologis, meyakinkan bahwa klien dapat menghadapi kehamilannya dan perubahan yang dirasakannya adalah sesuatu yang normal. Bidan harus bekerja sama dan membangun hubungan komunikasi yang baik dengan klien agar terjalin hubungan yang terbuka antara bidan dan klien. Ibu hamil yang selalu memikirkan mengenai keluarga, keuangan, perumahan dan pekerjaan dapat juga menimbulkan depresi dan perlu penanggulangan. Untuk itu bidan harus melakukan pengkajian termasuk keadaan lingkungan (latar belakang) sehingga mempermudah dalam melakukan asuhan kebidanan dan meningkatkan kualitas pelayanan ANC 10 terpadu di Puskesmas Bungus.

b. Pengetahuan ibu hamil

Sementara hasil wawancara dengan informan triangulasi didapatkan fakta bahwa sebagian besar masih memiliki pengetahuan yang rendah tentang pelayanan antenatal care 10 terpadu. Berdasarkan penelusuran lebih lanjut, penyuluhan dari petugas tentang pelayanan antentatal care 10 terpadu sudah terlaksana sesuai dengan jadwal maupun materi penyuluhan. Akan tetapi pada saat penyuluhan terkadang petugas kurang mampu mengontrol situasi, sehingga saat penyuluhan tidak semua ibu hamil mampu menangkap informasi dengan baik karena situasi yang kurang tenang.

Hasil penelitian ini juga sesuai dengan penelitian yang dilakukan oleh Anastasia (2017), dimana tingkat pengetahuan yang dimiliki oleh ibu tentang pelayanan kesehatan antenatal care masih didominasi oleh pengetahuan yang rendah.

Hal ini disebabkan karena kemampuan masyarakat dalam menyerap informasi masih belum maksimal, sehingga intensitas dan durasi penyuluhan yang dilakukan petugas belum memberikan hasil sesuai dengan yang diharapkan.

\section{Pelatihan}

Pengembangan diri diperlukan oleh setiap individu agar dapat meningkatkan produktivitas kerja suatu organisasi. Dalam rangka pengembangan diri dibutuhkan pelatihan yang berorientasi pada hasil, dengan kata lain pelatihan yang dilakukan harus sesuai dengan harapan yaitu 
menciptakan tenaga kerja yang dibutuhkan dalam organisasi. Berdasarkan hasil penelitian diketahui bahwa semua informan utama sudah pernah mendapatkan pelatihan dari Dinkes Kota Padang, namun untuk pelatihan pelayanan antenatal 10 Terpadu yaitu Pelatihan ANC Terpadu baru dapat diikuti oleh 3 informan utama. Dengan diadakannya pelatihan pelayanan antenatal 10 Terpadu diharapkan agar bidan mampu meningkatkan pengetahuan dan keterampilan bidan dalam memberikan pelayanan kesehatan kepada masyarakat khususnya pada ibu hamil.

Berdasarkan hasil penelitian diketahui bahwa menurut Kepala Puskesmas Bungus dan Pemegang Program KIA Puskesmas Bungus, terdapat perubahan perilaku pada bidan sebelum dan sesudah mengikuti pelatihan. Hal ini sejalan dengan teori manajemen sumber daya manusia Fathoni (2006 : 147) yang menyatakan bahwa pelatihan merupakan upaya untuk mentransfer keterampilan dan pengetahuan kepada para peserta pelatihan sedemikian rupa sehingga para peserta menerima dan melakukan pelatihan pada saat melaksanakan pekerjaan. Pengetahuan dan keterampilan yang dikembangkan harus spesifik dan pelatihan harus diarahkan pada perubahan perilaku yang diidentifikasikan. Pelatihan juga harus mempelajari keterampilan atau teknik khusus yang dapat didemonstrasikan dan diobservasi di tempat tugasnya.

\section{Dana}

Berdasarkan hasil penelitian diketahui bahwa tidak terdapat masalah dalam pembiayaan pelaksanaan pelayanan di Puskesmas Bungus. Sumber dana pada pelaksanaan pelayanan antenatal 10 Terpadu diperoleh dari pemerintah yakni dari APBD, BOK, dari masyarakat yakni melalui pembayaran langsung (fee for service) dari masyarakat yang kemudian disetorkan ke kas daerah, dan jaminan kesehatan nasional.

Adapun kegiatan yang berkaitan dengan kesehatan ibu hamil meliputi kegiatan pelayanan $\mathrm{ANC}$, pendampingan P4K, kelas ibu hamil, pelacakan kasus Bumil Resti, pelacakan kasus kematian ibu dan bayi, serta pembinaan program wajib persalinan di Puskesmas Bungus. Untuk kegiatan pendampingan $\mathrm{P} 4 \mathrm{~K}$, pelacakan kasus Bumil Resti, pelacakan kasus kematian ibu dan bayi menggunkan dana BOK untuk transportasi bidan puskesmas. Untuk kegiatan kelas ibu hamil dan pembinaan program wajib persalinan di Puskesmas Bungus menggunakan dana BOK untuk transportasi bidan puskesmas, 
serta konsumsi kegiatan. Sedangkan untuk kegiatan pelayanan ANC menggunakan dana APBD.

Pelaksanaan suatu program atau kegiatan dalam sebuah organisasi dapat berjalan dengan baik bila didukung dengan persediaan dana yang cukup. Demikian pula dengan pelayanan antenatal 10 Terpadu di Puskesmas yang akan terlaksana dengan baik bila didukung dengan pendanaan yang memadai.

Hasil penelitian ini sejalan dengan teori pembiayaan kesehatan Muninjaya (2011) yang menyebutkan bahwa terdapat empat sumber utama untuk membiayai pelayanan kesehatan yaitu pemerintah (APBN, APBD Provinsi, Kota/ Kota), swasta, masyarakat melalui pembayaran langsung atau yang terhimpun oleh perusahaan asuransi, dan hibah atau pinjaman luar negeri. Hal ini juga sejalan dengan Permenkes No 75 tahun 2014 pasal 42 ayat 1 yang menyebutkan bahwa pendanaan di Puskesmas bersumber dari APBD, APBN, dan sumber-sumber lain yang sah dan tidak mengikat.

\section{Sarana}

Ketersediaan sarana yang memadai sangat mendukung pelaksanaan pelayanan antenatal 10 Terpadu di Puskesmas. Menurut Elvira (2012 : 101) menyatakan bahwa lingkungan dan fasilitas serta alat merupakan faktor yang mendukung dalam melaksanakan kegiatan atau tindakan keberhasilan program yang dilaksanakan.

Hal ini sejalan dengan hasil penelitian Wanda (2015) yang menyatakan bahwa tidak adanya hubungan antara ketersediaan pelayanan kesehatan dengan pemanfaatan pelayanan antenatal 10 Terpadu, tidak adanya hubungan tersebut dikarenakan hampir seluruh responden menyatakan bahwa ketersediaan pelayanan kesehatan sudah cukup

Implementasi pelayanan antenatal 10 Terpadu di Puskesmas memang membutuhkan ketersediaan sarana yang lengkap. Dalam Permenkes RI No 75 tahun 2014 tentang Puskesmas pasal 15 ayat 1 menyebutkan bahwa peralatan kesehatan di Puskesmas harus memenuhi persyaratan standar mutu, keamanan, keselamatan, memiliki izin edar sesuai ketentuan peraturan perundang-undangan, serta diuji dan dikalibrasi secara berkala oleh institusi penguji dan pengkalibrasi yang berwenang. Hasil observasi yang dilakukan oleh peneliti, sarana yang dimiliki oleh Puskesmas Bungus dalam menyelenggarakan pelayanan antenatal 10 Terpadu sudah dapat berfungsi dengan baik. Semua sarana yang dimiliki pada 
pelayanan antenatal 10 Terpadu diperoleh melalui droping dari Dinkes Kota. Adapun bila dibandingkan dengan lampiran Permenkes RI No 75 tahun 2014 tentang Puskesmas.

Diketahui bahwa sebagian besar informan triangulasi baik ibu hamil yang rutin maupun tidak rutin mengakses pelayanan antenatal 10 Terpadu di Puskesmas Bungus menyatakan bahwa sarana yang dimiliki sudah memadai, namun perlu penambahan tenaga pengganti pada saat petugas mengikuti pelatihan karena pelayanan menjadi lebih lama dan mereka harus antri untuk mendapatkan pelayanan.

\section{SOP}

Berdasarkan hasil penelitian diketahui bahwa 7 informan utama menyatakan SOP pelayanan antenatal 10 Terpadu di Puskesmas Bungus disesuaikan dengan standar pelayanan 10 T. Penetapan standar $10 \mathrm{~T}$ sebagai pedoman dalam SOP pelayanan antenatal 10 Terpadu di Puskesmas Bungus sudah sesuai dengan kebijakan yang dikeluarkan oleh Kemenkes dan Dinkes Kota Padang. Adapun konten dalam SOP pelayanan antenatal 10 Terpadu di Puskesmas Bungus meliputi tujuan SOP, ruang lingkup SOP, definisi pelayanan, prosedur pelayanan, catatan mutu, indikator kerja, dan referensi.

Hasil penelitian ini sejalan dengan hasil pelatihan akreditasi FKTP (2015) yang disampaikan oleh Kepala Dinkes Kota Semarang (drg. M Gunardi, M.M) yang menyatakan bahwa penyusunan SOP dapat dikelola oleh tim mutu/tim akreditasi Puskesmas dengan mekanisme pelaksana/unit kerja menyusun SOP dengan melibatkan unit terkait, kemudian SOP tersebut disampaikan ke tim mutu Puskesmas untuk mendapatkan koreksi baik dari segi bahasa, tata tulis, maupun kebijakan yang digunakan. Setelah semua dikoreksi, kemudian ditetapkan oleh Kepala Puskesmas.

Tujuan dari SOP pelayanan antenatal 10 Terpadu di Puskesmas Bungus yaitu sebagai pedoman kerja bagi petugas kesehatan (bidan) dalam melaksanakan pelayanan antenatal 10 Terpadu pada ibu hamil. Ruang lingkup SOP pelayanan antenatal 10 Terpadu tersebut berlaku di lingkungan Puskesmas, Pustu, Poskesdes, dan Polindes. Catatan mutu implementasi pelayanan antenatal 10 Terpadu di Puskesmas Bungus dilakukan pada rekam medis, buku KIA, buku register ANC, buku register imunisasi, buku register HIV, dan register kohort ibu. Adapun indikator kerja yang diharapkan tercapai yaitu kehamilan 
terutama kesehatan ibu dan janin dapat dipantau, meningkatnya cakupan ANC, dan meningkatnya cakupan persalinan di Puskesmas.

SOP pelayanan antenatal 10 Terpadu di Puskesmas Bungus harus disesuaikan dengan kebijakan yang ditetapkan oleh Dinkes Kota Padang karena kedudukan Puskesmas Bungus adalah sebagai UPT Dinkes Kota Padang. Hal ini sesuai dengan Permenkes RI No 75 tahun 2014 tentang Puskesmas pasal 32 yang menyebutkan bahwa Puskesmas merupakan unit pelaksana teknis dinas kesehatan Kota/kota, sesuai dengan ketentuan peraturan perundang- undangan.

Berdasarkan hasil penelitian diketahui bahwa pembuatan SOP dilakukan oleh tim mutu Puskesmas. Proses pembuatan SOP diawali dengan berkumpulnya tim mutu Puskesmas yang mana sebelumnya sudah diadakan loka mini karya tingkat Puskesmas. Pada pertemuan tim mutu Puskesmas dilakukan penyusunan langkah-langkah yang harus dilakukan pada pelaksanaan pelayanan antenatal 10 Terpadu dan kebijakan pelayanan antenatal 10 Terpadu yang disesuaikan dengan pedoman yang telah ditentukan, kemudian didokumentasikan dalam bentuk catatan tertulis untuk memperoleh pengesahan dari Kepala Puskesmas.

Berdasarkan hasil penelitian diketahui bahwa SOP dapat digunakan atau berlaku selama 3 tahun. Pembaharuan SOP dilakukan ketika terdapat perubahan kebijakan pada pedoman yang dibuat oleh Kemenkes dan Dinkes Kota. Apabila tidak terdapat perubahan kebijakan maka proses pembaharuan SOP dilakukan pada tahap pendokumentasian untuk disahkan kembali oleh Kepala Puskesmas. Hal ini sesuai dengan Permenkes RI No 75 tahun 2014 tentang Puskesmas pasal 39 ayat 1 yang menyatakan bahwa dalam upaya peningkatan mutu pelayanan, Puskesmas wajib diakreditasi secara berkala paling sedikit 3 (tiga) tahun sekali.

Berdasarkan hasil observasi dan telaah dokumen yang dilakukan peneliti, pada tahun 2016 Puskesmas Bungus telah memiliki SOP dalam memberikan pelayanan antenatal 10 Terpadu dan sesuai dengan kebijakan terbaru yang dikeluarkan oleh Dinkes Kota Padang, namun SOP tersebut tidak diperbaharui setiap 3 tahun sekali baik dalam perihal pendokumentasian maupun prosedur pelaksanaan pelayanan antenatal 10 Terpadu yang seharusnya mengalami beberapa perubahan. Hal ini disebabkan 
karena tidak adanya kegiatan akreditasi yang dilakukan dalam kurun waktu tersebut. Pihak Puskesmas seharusnya tetap melakukan pembaharuan, karena dengan melakukan pembaharuan SOP maka Puskesmas akan memiliki SOP yang jelas dan sesuai dengan kebijakan yang terbaru, sehingga pelaksanaan pelayanan antenatal 10 Terpadu dapat dilakukan dengan standar yang semestinya. Hal ini sesuai dengan hasil penelitian Surya (2014) yang menyatakan bahwa penerapan langkahlangkah intervensi dalam rangka peningkatan keberhasilan pelayanan belum berjalan sesuai panduan klinis karena SPM yang belum dilakukan revisi secara berkala.

Implementasi pelayanan 10 terpadu di Puskesmas Bungus memang menjadi perhatian serius pihak puskesmas saat ini, selain untuk meningkatkan kualitas pelayanan kesehatan ibu hamil. Penerapan pelayanan 10 terpadu juga diprioritaskan untuk menekan angka kematian ibu hamil di wilayah ini, yang merupakan tertinggi di Kota Padang.

Pelayanan ANC di Puskesmas Bungus saat ini masih menerpakan prinsip kunjungan K1, K2, K3 dan K4. Frekuensi ini sesuai dengan rekomendasi dari WHO sebelumnya. Akan pada tahun 2016 Organisasi kesehatan dunia (WHO) merevisi panduannya mengenai perawatan antenatal.

\section{B. Komponen Process}

Proses merupakan suatu kegiatan yang berfungsi untuk mengubah masukan sehingga menghasilkan sesuatu (keluaran) yang direncanakan (Notoatmodjo, 2007). Menurut Sulaeman (2011) proses transformasi atau proses konversi yaitu proses mengubah masukan menjadi keluaran dengan melaksanakan fungsifungsi manajemen dan pelayanan kesehatan Puskesmas yang ditunjang oleh pelaksanaan standar mutu dan SOP serta sistem informasi manajemen Puskesmas. Pada penelitian ini komponen process terdiri dari 4 fungsi manajemen yaitu planning, organizing, actuating, dan controlling.

\section{Planning}

Fungsi perencanaan adalah fungsi terpenting dalam proses manajemen. Fungsi ini akan menentukan arah fungsi manajemen lainnya. Untuk itu, fungsi perencanaan merupakan landasan dasar pengembangan proses manajemen secara keseluruhan. Jika perencanaan tidak dirumuskan dan ditulis dengan jelas, proses manajemen tidak berjalan secara berurutan dan teratur. Dengan kata lain, perencanaan manajerial akan memberikan pola pandang 
secara menyeluruh terhadap pekerjaan yang dijalankan. Perencanaan merupakan tuntunan proses untuk mencapai tujuan secara efisien dan efektif (Muninjaya, 2011 ).

Berdasarkan hasil penelitian dapat diketahui bahwa perencanaan pelayanan antenatal 10 Terpadu di Puskesmas Bungus dilakukan melalui loka mini karya tingkat Puskesmas dan melalui musyawarah dengan lintas sektoral. Loka mini karya tingkat Puskesmas dilakukan setiap satu bulan sekali, sedangkan musyawarah lintas sektoral dilakukan setiap 3 bulan sekali. Hal ini sejalan dengan teori perencanaan Sulaeman (2011) yang menyatakan bahwa pelaksanaan perencanaan tingkat Puskesmas diantaranya yaitu menyusun usulan kegiatan tahunan untuk musyawarah perencanaan pembangunan (Musrenbang) tingkat kecamatan dan dilaksanakan secara terus menerus dan berkesinambungan.

\section{Organizing}

Pengorganisasian adalah mengatur personel atau staf yang ada dalam institusi tersebut agar semua kegiatan yang telah ditetapkan dalam rencana tersebut dapat berjalan dengan baik, yang akhirnya semua tujuan dapat tercapai. Dengan kata lain pengorganisasian adalah pengkoordinasian kegiatan-kegiatan yang akan dilakukan suatu institusi, guna mencapai tujuan yang telah ditetapkan (Notoatmodjo, 2007 ).

Berdasarkan hasil penelitian diketahui bahwa terdapat pengorganisasian pada pelayanan antenatal 10 Terpadu di Puskesmas Bungus melalui pendelegasian wewenang dari Kepala Puskesmas kepada bidan dalam bentuk jadwal pemberian pelayanan antenatal 10 Terpadu oleh bidan Puskesmas. Setiap hari pemberian pelayanan antenatal 10 Terpadu di Puskesmas Bungus dilakukan oleh 3 orang bidan, 1 bidan sebagai petugas administrasi, 1 bidan sebagai petugas pemeriksaan, dan 1 bidan lainnya sebagai petugas pengelolaan Simpus.

Hasil penelitian ini sejalan dengan teori pengorganisasian Muninjaya (2011) yang menyatakan bahwa wewenang adalah kekuasaan atau hak yang diberikan kepada seseorang dalam sebuah organisasi untuk memerintah atau meminta orang lain untuk berbuat sesuatu. Wewenang seseorang dalam sebuah organisasi dibatasi dalam bentuk uraian tugasnya sesuai dengan tugas pokok dan fungsi serta kedudukannya di dalam organisasi. Wewenang dapat didelegasikan kepada staf bawahan, tetapi manajer tetap bertanggung jawab penuh terhadap keberhasilan atau kegagalan tugas yang dilaksanakan oleh staf meskipun 
sebagian wewenangnya sudah didelegasikan kepada stafnya.

\section{Actuating}

\section{a. Alur Pelayanan}

Berdasarkan hasil penelitian diketahui bahwa alur pelayanan antenatal 10 Terpadu di Puskesmas Bungus sudah sesuai dengan alur yang ditetapkan oleh Kemenkes RI pada buku pedoman ANC Terpadu.

Alur pelayanan antenatal 10 Terpadu di Puskesmas Bungus dimulai dengan pendaftaran di loket, kemudian ke poli KIA untuk mendapatkan pemeriksaan, jika ditemukan indikasi diperlukannya pemeriksaan laboratorium maka ibu hamil direkomendasikan ke ruang laboratorium. Ibu hamil kembali ke poli KIA dengan membawa hasil pemeriksaan laboratorium untuk dilakukan konseling hasil laboratorium, setelah itu ibu hamil dapat ke kamar obat untuk mengambil obat kemudian pulang. Jika hasil laboratorium menunjukkan bahwa ibu hamil memiliki kelainan atau gangguan kesehatan pada kehamilannya maka ibu hamil dirujuk ke dokter Puskesmas, dan bila diperlukan dirujuk ke dokter spesialis kandungan di rumah sakit.

\section{b. Tindakan Medis (10T)}

Berdasarkan hasil penelitian diketahui bahwa implementasi pelayanan antenatal 10 Terpadu di Puskesmas Bungus berpedoman pada standar pelayanan 10T. Berdasarkan hasil penelitian, pada dasarnya bidan Puskesmas dan bidan desa sudah memahami untuk menerapkan standar $10 \mathrm{~T}$ pada pelayanan antenatal 10 Terpadu, namun pada pelaksanaannya masih terdapat tindakan yang belum dilakukan secara teratur, yaitu pemberian konseling karena bidan Puskesmas tidak secara rutin memberikan konseling jika ibu hamil tidak mengalami keluhan. Adapun pokok bahasan konseling yang belum diberikan secara teratur oleh bidan yaitu mengenai peran suami/keluarga, gejala penyakit menular dan tidak menular, serta tanda bahaya pada kehamilan. Meskipun demikian, pokok bahasan konseling yang masih belum diberikan secara teratur dalam implementasi pelayanan antenatal 10 Terpadu di Puskesmas tersebut, diberikan oleh bidan kepada ibu hamil dalam pelaksanaan kegiatan lain, yaitu pada kegiatan kelas ibu hamil.

Hal ini belum sesuai dengan ketetapan Kemenkes RI tahun 2010 yang tertera pada pedoman ANC terpadu. Menurut Kemenkes RI tahun 2010 konseling terdiri dari kesehatan ibu, PHBS, peran suami/keluarga, tanda bahaya pada 
kehamilan, persalinan dan nifas serta implementasi pelayanan antenatal 10 kesiapan menghadapi komplikasi, asupan gizi seimbang, gejala penyakit menular dan tidak menular, IMD dan pemberian ASI eksklusif, KB paska persalinan, imunisasi, peningkatan intelegensia pada kehamilan.

Berdasarkan hasil pengamatan yang dilakukan oleh peneliti, bidan tidak melakukan beberapa pokok bahasan konseling dikarenakan mengingat jumlah pasien yang datang pada pelayanan antenatal 10 Terpadu. Kondisi ini sering terjadi pada saat jumlah kunjungan ibu hamil banyak, sementara tenaga bidan dibebani dengan program-program yang lain dari pemerintah Kota, sehingga durasi pelayanan kurang maksimal. Bila semua item dalam standar 10T pelayanan antenatal 10 Terpadu termasuk didalamnya KIE efektif dilakukan oleh bidan maka pemberian pelayanan antenatal 10 Terpadu akan memakan waktu yang lama dan akan membuat ibu hamil menunggu lebih lama. Hal ini sejalan dengan hasil penelitian Dhiah (2010 : 96) yang menyatakan bahwa rata-rata keseluruhan dari skor informasi dan konseling adalah $68,65 \%$ dan ada beberapa item yang tidak dilakukan bidan karena mengingat pasien yang banyak.

Berdasarkan hasil observasi yang dilakukan oleh peneliti, diketahui bahwa Terpadu di Puskesmas Bungus pada trimester I meliputi timbang berat badan, ukur tekanan darah, ukur LiLA, skrining status imunisasi TT, pemberian tablet $\mathrm{Fe}$, pemeriksaan laboratorium, KIE efektif, dan tata laksana kasus jika pada hasil pemeriksaan ditemukan kasus risiko kehamilan. Pada kunjungan trimester II implementasi pelayanan antenatal 10 Terpadu meliputi timbang berat badan, ukur tekanan darah, menentukan tinggi fundus uteri, presentasi janin dan denyut jantung janin, pemberian tablet $\mathrm{Fe}$, KIE efektif, pemeriksaan laboratorium dan penatalaksanaan kasus jika ditemukan kasus risiko pada kehamilan. Sedangkan pada kunjungan trimester III implementasi pelayanan antenatal 10 Terpadu meliputi timbang berat badan, ukur tekanan darah, menentukan tinggi fundus uteri, presentasi janin dan denyut jantung janin, pemberian tablet $\mathrm{Fe}$, pemeriksaan laboratorium, KIE efektif, dan penatalaksanaan kasus jika ditemukan kasus risiko pada kehamilan.

Hasil penelitian ini sejalan dengan ketetapan Kemenkes RI (2010) yang menyatakan bahwa pemeriksaan pelayanan antenatal 10 Terpadu yang rutin dilakukan pada trimester I, II, dan III meliputi timbang berat badan, ukur tekanan darah, 
pemberian tablet $\mathrm{Fe}$, penatalaksanaan kasus, dan KIE efektif. Pemeriksaan yang hanya dilakukan pada trimester I yaitu mengukur tinggi badan, LiLA, dan cek golongan darah. Pemeriksaan rutin yang dilakukan pada trimester I dan III yaitu cek kadar $\mathrm{Hb}$ dalam darah. Sedangkan pemeriksaan yang dilakukan pada trimester II dan III yaitu mengukur tinggi fundus uteri, menentukan presentasi janin dan denyut jantung janin.

\section{c. Tindakan Non Medis (Pencatatan dan Pelaporan)}

Berdasarkan hasil observasi yang dilakukan peneliti, ditemukan bahwa setiap ibu hamil yang mengakses pelayanan antenatal 10 Terpadu selalu dilakukan pencatatan oleh bidan pada buku register pasien, rekam medis, buku KIA, dan register kohort ibu. Jika ibu mendapatkan imunisasi maka pencatatan juga dilakukan pada buku imunisasi Puskesmas. Selain itu, berdasarkan hasil telaah dokumen diketahui bahwa terdapat laporan bulanan capaian program KIA, PWS KIA, dan PWS imunisasi.

Hasil penelitian ini sejalan dengan ketetapan Kemenkes RI (2010) yang menyebutkan bahwa pencatatan pelayanan antenatal 10 Terpadu menggunakan formulir yang sudah ada yaitu kartu ibu atau rekam medis lainnya yang disimpan di fasilitas kesehatan, register kohort ibu, buku KIA, dan pencatatan dari program yang sudah ada (catatan dari imunisasi, malaria, gizi, KB, TB, dll.). Sedangkan pelaporan pelayanan antenatal 10 Terpadu menggunakan formulir pelaporan yang sudah ada yaitu LB3 KIA, PWS KIA, PWS imunisasi, atau untuk lintas program terkait pelaporan mengikuti formulir yang ada pada program tersebut.

\section{Controlling}

Berdasarkan hasil penelitian diketahui bahwa pengawasan implementasi pelayanan antenatal 10 Terpadu dilakukan oleh Kepala Puskesmas melalui kegiatan apel pagi di setiap hari kerja, dan melalui pertemuan intern Puskesmas setiap bulan. Pengawasan dari Dinkes Kota Padang dilakukan dalam bentuk laporan bulanan hasil capaian pelayanan antenatal 10 Terpadu, serta dilakukan monev setiap 3 bulan sekali di Dinkes Kota. Selain itu, dari Dinkes Kota juga melakukan supervisi fasilitatif minimal 2 kali dalam 1 tahun. Sedangkan pengawasan pelaksanaan pelayanan antenatal 10 Terpadu di desa dilakukan oleh Bikor Puskesmas melalui peninjauan langsung terkait implementasi pelayanan antenatal 10 Terpadu di Pustu, Poskesdes, maupun Polindes. 
Hasil penelitian ini sejalan dengan Permenkes No 75 tahun 2014 tentang Puskesmas yang menyatakan bahwa pemerintah, pemerintah daerah provinsi, dan pemerintah daerah Kota/kota serta fasilitas pelayanan kesehatan rujukan tingkat lanjutan milik pemerintah dan pemerintah daerah melakukan pembinaan dan pengawasan terhadap penyelenggaraan Puskesmas, sesuai dengan tugas dan fungsi masing-masing.

Hasil penelitian ini juga sejalan dengan teori manajemen kesehatan Muninjaya (2011 : 111-113) yang menyatakan terdapat 3 jenis pengawasan yaitu pengawasan fungsional, pengawasan publik, dan pengawasan non fungsional. Fungsi pengawasan fungsional melekat pada seseorang yang memiliki jabatan lebih tinggi pada struktur organisasi. Tugas pokok setiap pimpinan adalah melakukan pengawasan terhadap kegiatan staf yang ada di unit kerja yang dipimpinnya. Pemimpin dalam melakukan fungsi pengawasan perlu mengumpulkan data/fakta yang dapat diperoleh melalui pengamatan langsung, laporan lisan, maupun laporan tertulis.

Berdasarkan uraian di atas dapat disimpulkan bahwa pada pengawasan dan pengendalian implementasi pelayanan antenatal 10 Terpadu di Puskesmas Bungus dilakukan melalui pengawasan fungsional yaitu oleh Kepala Puskesmas dan Dinkes Kota Padang. Pengumpulan data dilakukan melalui pengamatan langsung ke fasilitas kesehatan atau supervisi fasilitatif oleh Dinkes Kota, laporan lisan oleh bidan kepada Kepala Puskesmas melalui kegiatan apel pagi di Puskesmas, dan laporan tertulis dalam bentuk laporan bulanan hasil capaian pelayanan antenatal 10 Terpadu.

\section{Komponen Output}

\section{Cakupan Pelayanan antenatal 10 Terpadu}

Berdasarkan hasil telaah dokumen laporan bulanan ANC Puskesmas Bungus pada bulan Januari s.d. Juni tahun 2019 diketahui bahwa cakupan K1 dan K4 mengalami kenaikan. Adapun cakupan pada bulan Januari yaitu 98\% untuk K1 dan 95,8\% untuk K4, 98,5\% untuk $\mathrm{K} 1$ dan 95,5\% untuk K4 pada bulan Februari, 98,9\% untuk K1 dan 96\% untuk K4 pada bulan Maret, 98,8\% untuk K1 dan 96\% untuk K4 pada bulan April. 98,5\% untuk K1 dan 95,5\% untuk K4 pada bulan Mei. 98,8\% untuk K1 dan 96\% untuk K4 pada bulan Juni.

Menurut hasil penelitian Wanda (2015:50) menyatakan bahwa Puskesmas sudah seharusnya meningkatkan cakupan 
terhadap pelayanan antenatal 10 Terpadu ke masyarakat supaya dapat meningkatkan ibu hamil sehat. Berdasarkan hasil penelitian diketahui bahwa angka cakupan K4 Puskesmas Bungus tersebut mengalami peningkatan bila dibandingkan dengan tahun. Meskipun demikian masih terdapat beberapa kelurahan dengan capaian $\mathrm{K} 4$ dibawah $95 \%$. Penyebab tidak terpenuhinya target cakupan 95\% di setiap desanya berbeda-beda. Seperti karena terdapat beberapa ibu hamil yang belum memasuki umur kehamilan 7 bulan ke atas sehingga belum dapat dimasukkan ke dalam cakupan K4. Tingkat kepatuhan masyarakat terhadap kebijakan aturan kunjungan K4 yang masih kurang. Adanya kebijakan Puskesmas yang mewajibkan ibu hamil untuk melakukan proses persalinan di Puskesmas, sehingga ibu hamil lebih memilih melakukan pemeriksaan kehamilan di fasilitas kesehatan lain. Tingkat kepatuhan masyarakat terhadap kebijakan aturan kunjungan K4 yang masih kurang,

\section{Kesesuaian dengan SOP}

Berdasarkan hasil observasi yang dilakukan oleh peneliti, diketahui bahwa implementasi pelayanan antenatal 10 Terpadu di Puskesmas Bungus sudah sesuai dengan SOP yang berlaku. Implementasi pelayanan antenatal 10 Terpadu di Puskesmas Bungus masih terdapat beberapa pokok bahasan konseling yang belum diberikan kepada ibu hamil secara teratur, seperti peran suami/keluarga, gejala penyakit menular dan tidak menular, serta tanda bahaya pada kehamilan. Akan tetapi pokok bahasan konseling yang masih belum diberikan secara teratur dalam implementasi pelayanan antenatal 10 Terpadu di Puskesmas tersebut, diberikan oleh bidan kepada ibu hamil dalam pelaksanaan kegiatan lain, yaitu pada kegiatan kelas ibu hamil.

Hal tersebut dikarenakan panjangnya proses asuhan kebidanan. Apabila bidan menerapkan standar 10T pelayanan antenatal 10 Terpadu maka akan memakan waktu lebih dari 30 menit untuk memberikan pelayanan pada tiap ibu hamil. Sedangkan ibu hamil yang datang ke Puskesmas sering kali jumlahnya melebihi 20 orang dan datang pada waktu yang hampir bersamaan, sehingga ibu hamil yang datang ke Puskesmas akan menunggu lebih lama lagi.

Implementasi program jaminan mutu di Puskesmas adalah dalam bentuk penerapan standar dan prosedur tetap pelayanan, agar hasil implementasi yang diperoleh tetap terjaga kualitasnya, 
meskipun pada kondisi lingkungan dan petugas bergantian. Dengan demikian sudah seharusnya tiap bidan dalam kondisi apapun tetap menerapkan pelayanan yang disesuaikan dengan SOP yang berlaku. Hasil penelitian ini sejalan dengan hasil penelitian Myrra dan Ratna (2013) yang menyatakan bahwa bidan sudah seharusnya memberikan pelayanan yang sesuai dengan SOP untuk meningkatkan kepatuhan bidan supaya bidan tidak salah dalam memberikan pelayanan.

\section{KESIMPULAN}

Berdasarkan hasil penelitian yang telah dibahas pada bab sebelumnya, maka kesimpulan yang dapat ditarik oleh peneliti adalah sebagai berikut :

1. Komponen input

a. Bidan Puskesmas sudah memahami untuk menerapkan standar $10 \mathrm{~T}$ pada pelayanan antenatal 10 Terpadu, namun pada pelaksanaannya masih terdapat beberapa bidan yang tidak selalu bisa melayani karena harus mengikuti pelatihan. Pelatihan pelayanan antenatal 10 Terpadu yang diadakan oleh Dinas Kesehatan Kota Padang yaitu Pelatihan ANC Terpadu baru dapat diikuti oleh 3 informan utama.

b. Dalam menyelenggarakan pelayanan antenatal 10 Terpadu tidak terdapat permasalahan mengenai dana dikarenakan pembiayaan bersumber dari pemerintah yaitu dari anggaran pendapatan dan belanja daerah (APBD), bantuan operasional kesehatan (BOK), pembayaran langsung (fee for service) dari masyarakat yang kemudian disetorkan ke kas daerah, dan jaminan kesehatan nasional

c. Sarana yang dimiliki oleh Puskesmas Bungus untuk pelayanan ANC 10 terpadu sudah lengkap dan berfungsi dengan baik dan bisa digunakan untuk semua ibu hamil dan melahirkan yang datang berkunjung

d. SOP pelayanan antenatal 10 Terpadu di Puskesmas Bungus disesuaikan dengan standar pelayanan 10 T. SOP mengalami pembaharuan s $137 \quad 3$ tahun sekali.

2. Komponen process

1. Perencanaan pelayanan antenatal 10 Terpadu di Puskesmas Bungus dilakukan melalui loka mini karya tingkat Puskesmas dan melalui musyawarah dengan lintassektoral.

2. Pengorganisasian pada pelayanan 
antenatal 10 Terpadu di Puskesmas Bungus melalui pendelegasian wewenang dari Kepala Puskesmas kepada bidan dalam bentuk jadwal pemberian pelayanan antenatal 10 Terpadu oleh bidan Puskesmas

3. Alur pelayanan antenatal 10 Terpadu dimulai dengan pendaftaran, kemudian pemeriksaan di bidan, pemeriksaan

laboratorium,USG,konseling

,pemberian obat, kemudian pulang.

Bidan sudah menerapkan standar 10T pada implementasi pelayanan antenatal 10 Terpadu di Puskesmas Bungus. Pencatatan pelayanan antenatal 10 Terpadu dilakukan pada buku KIA ibu hamil dan buku ANC. Sedangkan pelaporan dilakukan dalam bentuk register kohort ibu yang diserahkan ke Bikor program kesehatan ibu

4. Masih terdapat hambatan yang terjadi pada implementasi pelayanan antenatal 10 Terpadu di Puskesmas Bungus, baik hambatan yang bersumber pada kurang maksimalnya pelayanan dari bidan di Puskesmas karena beban kerja juga ditambah dengan berbagai program-program dari Dinas Kesehatan yang harus dilakukan oleh bidan. Selain itu juga ada pada lingkungan yaitu jangkauan rumah penduduk yang jauh dari Puskesmas sementara ketersediaan waktu kunjungan dan pelayanan tidak mencukupi

5. Laporan bulanan hasil capaian pelayanan antenatal 10 Terpadu yang diserahkan ke Dinkes Kota Padang

3. Komponen output

a. Berdasarkan hasil telaah dokumen laporan bulanan ANC Puskesmas Bungus pada bulan Januari s.d. Juni tahun 2019 diketahui bahwa cakupan K1 dan K4 mengalami kenaikan. Adapun cakupan pada bulan Januari yaitu 98\% untuk K1 dan 95,8\% untuk K4, 98,5\% untuk K1 dan 95,5\% untuk K4 pada bulan Februari, 98,9\% untuk K1 dan 96\% untuk K4 pada bulan Maret, 98,8\% untuk K1 dan 96\% untuk K4 pada bulanApril. 98,5\% untuk K1 dan 95,5\% untuk K4 pada bulanMei. 98,8\% untuk K1 dan 96\% untuk K4 pada bulanJuni

b. Implementasi pelayanan antenatal 10 Terpadu di Puskesmas Bungus sudah sesuai dengan SOP yang berlaku

\section{UCAPAN TERIMA KASIH}

Trima kasih kepada Dinas Kesehatan kota Padang atas kesempatan yang diberikan 
kepada penulis untuk melakukan penelitian khusunya di Pusksmas Bungus Kota Padang

\section{DAFTAR RUJUKAN}

1. Abera. 2018. Pregnant women adherence level to antenatal care visit and its effect on perinatal outcome among mothers in Tigray Public Health institutions, 2017: cohort study. doi: 10.1186/s13104-0183987-0

2. Anastasia. 2017. Analisis Pelayanan Antenatal dan Faktor - Faktor yang Berkaitan dengan Cakupan Pelayanan Antenatal oleh Bidan Desa Di Kabupaten Jember. Volume 5, Nomor 1, Januari 2017 (ISSN: 2356-3346)

3. Anna Mieke. 2013. Analisis Implementasi Program Pelayanan Antenatal Terpadu pada Ibu Hamil dengan Malaria di Puskesmas Tobelo Kabupaten Halmahera Utara Provinsi Maluku Utara. Volume 01 No.02 Agustus 2013

4. Ambarwati. E.R.. dan Rismintari Y.S. 2009. Asuhan Kebidanan Komunitas. Cetakan I. Nuha Medika. Yogyakarta

5. Anik Sulistiyanti. 2015. Kajian Pelaksanaan Pelayanan Antenatal Care Oleh Bidan di Wilayah Kerja Puskesmas Masaran Sragen. Akbid Citra Medika Surakarta. Infokes. Vol. 5 No. 2 September 2015

6. Arikunto Suharsimi. 2010. Prosedur Penelitian Suatu Pendekatan Praktik. Jakarta: Rineka Cipta

7. Bappenas. 2018. Buku Penguatan Pelayanan Kesehatan Dasar di PuskesmasDirektorat Kesehatan dan Gizi Masyarakat. Jakarta. Bappenas
8. Dinas Kesehatan Kota Padang. 2017. Profil Kesehatan Kota Padang.

9. Dinkes Sumbar. 2017. Profil Dinas Kesehatan Tahun 2017. Padang. Dinkes Prop. Sumbar

10. Elmispendriya Gusna. 2016. Analisis Cakupan Antenatal Care K4 Program Kesehatan Ibu dan Anak di Wilayah Kerja Dinas Kesehatan Kabupaten Padang Pariaman. Jurnal Kesehatan Andalas. 2016; Vol. 5 No. 1

11. Fathoni Abdurahmat. 2006. Manajemen Sumber Daya Manusia. Bandung : Rineka. Cipta

12. Handoko T Hani. 2012. Manajemen Personalia dan Sumber Daya Manusia. Yogyakarta: BPFE

13. Heba H Hijazi . 2018. The Impact of Applying Quality Management Practices on Patient Centeredness in Jordanian Public Hospitals: Results of Predictive Modeling. The Journal of Health Care Organization, Provision, and Financing Volume 55: 1-15

14. Herdiansyah. Haris. 2013. Wawancara Observasi dan Fokus Groups Sebagai Instrumen Penggalian Data Kualitatif. Jakarta : Rajawali Press

15. Kemenkes RI. 2010. http://kesga.kemkes.go.id/ images/pedoman/ PMK\% 20No .\% 2097 $\% 20 \operatorname{ttg} \% 20 \quad$ Pelayanan\%20 Kesehatan\%20 Kehamilan.pdf

16. Kemenkes RI. 2017. Profil Kesehatan Indonesia Tahun 2017. Jakarta. Kementerian Kesehatan Republik Indonesia

17. Lisa Marniyati. 2016. Pelayanan Antenatal Berkualitas dalam Meningkatkan Deteksi Risiko Tinggi pada 
Ibu Hamil oleh Tenaga Kesehatan di Puskesmas Sako. Sosial. Sei Baung dan Sei Selincah di Kota Palembang. Program Pascasarjana Ilmu Kesehatan Masyarakat Universitas Sriwijaya. Palembang. Jurnal Kedokteran dan Kesehatan. Volume 3. No. 1. Januari 2016:355-362

18. M. Mazharul Islami. 2018. Determinants of frequency and contents of antenatal care visits in Bangladesh: Assessing the extent of compliance with the WHO recommendations. https://doi.org/10.1371/journal.pone.0204 $752 \mathrm{~S}$

19. Moleong Lexy J. 2012. Metodologi Penelitian Kualitatif. Bandung : PT Remaja. Rosdakarya

20. Muninjaya Gde.AA. 2011. Manajemen Mutu Pelayanan Kesehatan. Jakarta. EGC

21. Nurmawati. 2017. Faktor-Faktor yang Berhubungan dengan Kehamilan Resiko Tinggi di Puskesmas Cibatu Kabupaten Bekasi Provinsi Jawa Barat Tahun 2017. Fakultas Ilmu Kesehatan. Universitas Nasional. Jurnal Ilmu dan Budaya. Edisi Khusus Fakultas Ilmu Kesehatan. Vol. 40. No.57/ 2017

22. Peraturan menteri kesehatan republik indonesia Nomor 43 tahun 2016 Tentang Standar Pelayanan Minimal Bidang Kesehatan

23. Peraturan Menteri Kesehatan Republik Indonesia. Nomor 75 Tahun 2014. Tentang. Pusat Kesehatan Masyarakat.

24. Prasetyawati. 2012. Kesehatan Ibu dan Anak (KIA). Yogyakarta. Nuha Medika

25. Prawirohardjo. S. 2006. Buku Acuan Nasional Pelayanan Kesehatan Maternal dan Neonatal. Jakarta : Yayasan Bina Pustaka

26. Romauli. Suryati. 2011. Buku Ajar ASKEB I: "Konsep Dasar Asuhan Kehamilan". Yogyakarta: NuhaMedika.

27. Ruwayda. 2016. Pelaksanaan Standar Pelayanan Antenatal Oleh Bidan di Puskesmas Kota Jambi. Jurusan Kebidanan Poltekes Kemenkes Jambi. Jurnal MKMI Vol. 12 No. 2 Juni 2016

28. Saifuddin. Abdul Bari. 2006. Buku Ilmu Kebidanan Sarwono Prawirohardjo. Jakarta: Yayasan Bina Pustaka Sarwono Prawirohardjo.

29. Salmah. 2006. Asuhan Kebidanan Pada Antenatal. Jakarta: EGC.

30. Sugiyono. 2014. Metode Penelitian Kuantitatif Kualitatif dan R\&D. Bandung : Alfabeta.

31. Sulaeman. 2011. Manajemen Kesehatan Teori dan Praktek di Puskesmas Revisi. Yogyakarta : Gajah Mada University Press

32. Trihono. 2005. Manajemen Puskesmas Berbasis Paradigma Sehat. Jakarta: CV Sagung Seto

33. U Mariati. 2011. Studi Kematian Ibu dan Kematian Bayi di Provinsi Sumatera Barat: Faktor Determinan dan Masalahnya. Jurusan Kebidanan Politeknik Kesehatan Kementerian Kesehatan Padang. **Fakultas Kedokteran Universitas Andalas. Kesmas. Jurnal Kesehatan Masyarakat Nasional Vol. 5. No. 6. Juni 2011

34. Varadina Ayu. 2016. Model Pelayanan Kesehatan (Studi Deskriptif Tentang Model Pelayanan Program Antenatal care di Puskesmas Peterongan Kabupaten Jombang). Program Studi Ilmu 
Administrasi Negara. FISIP. Universitas Airlangga. ISSN 2303 - 341X. Volume 4. Nomor 3. September - Desember 2016

35. Yaya S .2017. Timing and adequate attendance of antenatal care visits among women in Ethiopia. Doi: 10.1371/journal.pone.0184934. eCollection 2017.

36. Winarno Budi. 2008. Kebijakan Publik : Teori dan Proses. Jakarta: PT Buku Kita

37. World Health Organization. 2018. WHO recommendation on antenatal care contact schedules.

38. https://extranet.who.int/rhl/topics/improvi ng-health-system-performance/whorecommendation-antenatal-care-contactschedules 